\title{
Pluralist action research: a review of the information systems literature*
}

\author{
Mike Chiasson, ${ }^{*}$ Matt Germonprez ${ }^{\dagger} \&$ Lars Mathiassen ${ }^{\ddagger}$ \\ *Department of Management Science, Management School, Lancaster University, \\ Lancaster, UK, email: m.chiasson@lancaster.ac.uk, 'Information Systems, College of \\ Business, University of Wisconsin - Eau Claire, Eau Claire, WI, USA, email: \\ germonr@uwec.edu, and ${ }^{\ddagger}$ Computer Information Systems, J. Mack Robinson College of \\ Business, Georgia State University, Atlanta, GA, USA, email: Imathiassen@gsu.edu
}

\begin{abstract}
Action research (AR) has for many years been promoted and practised as one way to conduct field studies within the information systems (IS) discipline. Based on a review of articles published in leading journals, we explore how IS researchers practise $A R$. Our review suggests that $A R$ lends itself strongly towards pluralist approaches which facilitate the production of both theoretical and practical knowledge. First, on the level of each study we analyse how research and problem-solving activities are mixed, in three ways: the research dominant, the problem-solving dominant and the interactive approaches. Second, in the context of the wider research programme in which the study is situated, we analyse how $A R$ is mixed with other research methods, in two ways: the dominant and the sequential approaches. We argue that these pluralist practices of mixing types of research activities and types of research methods provide IS action researchers with a rich portfolio of approaches to knowledge production. This portfolio helps them address the risks involved in AR to ensure their efforts contribute to the literature as well as to practical problem-solving.
\end{abstract}

Keywords: action research, IS research methodology, pluralism

\section{INTRODUCTION}

In research, as in practice, information systems (IS) researchers use specific approaches to generate knowledge in response to particular questions and problems. In doing so, they are confronted with a series of choices and information about particular approaches, and the knowledge that could arise from each. As a result, researchers may start with one approach, and while accepting the partial results it provides, run other research approaches sequentially, in parallel, and at different levels of analysis, in order to increase the understanding of a

\footnotetext{
*Corrections added on 6 October 2008 after first online publication. On page 18, line 6, 'Davison \& Martinsons, 2006' was amended to 'Davison \& Martinsons, 2007'. On page 23, Appendix, in the sixth row of 'MISQ', 'Iversen, Mathiassen \& Nielson' was amended to 'Iversen, Mathiassen \& Nielsen'.
} 
phenomenon (Mingers, 2001). We lack, however, knowledge about how approaches are mixed in IS action research (AR) in order to adequately address the questions and problems of interest (McKay \& Marshall, 2001) while managing the practical and research-related risks (Baskerville \& Wood-Harper, 1996).

There are particular challenges and opportunities related to AR. It 'aims to contribute both to the practical concerns of people in an immediate problematic situation and to the goals of social science' (Rapoport, 1970, p. 499). This dual agenda implies that action researchers need to take advantage of different approaches to effectively contribute to both practical problem-solving and the goals of social science (McKay \& Marshall, 2001). While AR has been practised within the IS discipline for some time (Lau, 1997; Baskerville \& Wood-Harper, 1998), it has recently attracted increasing attention as an important method for developing both practically relevant and theoretically interesting contributions, based on the careful and reflexive use of a variety of approaches [Information Technology \& People (ITP) special issue editorial (14:1) 2001; Mathiassen (2002); MIS Quarterly (MISQ) special issue editorial (28:3) 2003]. We know, however, little about how IS action researchers use and combine different approaches to generate knowledge which serves both the practical needs of an immediate problematic situation and the theoretical needs within the IS discipline.

The purpose of this research is to investigate the role of pluralist approaches in AR involving the mixing of research cycles and problem-solving cycles within AR (McKay \& Marshall, 2001) as well as the mixing of AR with other research methods (Mingers, 2001) where methods are understood as an approach for producing explanation (Hovorka et al., 2008). To address these two issues, we have conducted a systematic review of AR publications in leading IS journals. While there are some reviews of the IS AR available (Lau, 1997; Baskerville \& Wood-Harper, 1998), they do not include recent AR publications and they do not provide a systematic review of how these studies mixed research and problem-solving activities and methods. As described in detail below, we have identified a total of 63 AR-based articles in leading IS journals. We first present a conceptual understanding of how approaches mix cycle activities and methods in developing and presenting AR contributions within our discipline. This analysis is focused on the level of each AR study and it investigates how research and problem-solving cycles are mixed and interact during AR studies. Second, we focus on the wider research programme in which the AR is situated and investigate how AR is mixed with other research methods to produce knowledge for IS practice and theory.

The first analysis of the literature builds on the work of McKay \& Marshall (2001), which suggests that action researchers should consider two parallel and interacting cycles: the research cycle (focused on the scientific goals) and the problem-solving cycle (focused on the problematic situation). Problem-solving represents problems that are both discovered and solved (Simon, 1981), problems interpreted by stakeholders in unstructured situations (Checkland, 1981) as well as problems that are critical theoretical in nature (Habermas, 1981). This distinction helps researchers manage the dual goals of AR (Rapoport, 1970) through the enactment of appropriate problem-solving and research activities. Based on this analysis, we found different ways in which research and problem activities were mixed: the research dominant, the problem-solving dominant, and the interactive approaches. 
Our second analysis uses concepts from John Mingers (2001) to study the use of multiple research methods in IS AR, and to explain how this leads to theoretical contributions. Mingers (2001) proposes mixing research methods as a way of moving from an original appreciation of a research study, towards action that implements the findings. Where one research method falls short along this path, another can succeed. Based on our analysis of the literature, we found that AR studies use both dominant and sequential approaches to mixing research methods. The dominant approach uses AR from the outset of a research programme, in combination with other conventional research methods, to explore the relevance of IS theory and study findings in particular research settings. In other situations, AR emerges as a complementary method embedded within a larger research programme allowing the researchers to explore and extend earlier findings through its implementation within practical contexts.

Our findings have important implications for IS AR methodology and practice. Baskerville \& Wood-Harper (1996) have summarized important risks related to AR: (1) lack of impartiality of the researcher; (2) lack of discipline; (3) often mistaken for consulting; and (4) contextdependency leading to difficulty in generalizing study findings. Many IS researchers hesitate for these reasons to include AR in their repertoire of research methods, and younger colleagues are often warned that the use of AR might slow down or damage their career. We argue, based on the findings from the review of the literature that AR lends itself strongly towards many forms of pluralist approaches to research. These insights provide valuable guidance for IS researchers on how to manage the risks related to AR so they can effectively address the practical needs in problematic situations while at the same time contributing to IS theory.

Our argument is structured as follows. In the next section, we review the theoretical background for this study. Then we present the research questions and methods that guided our analysis of the literature. We then discuss the conceptual understanding of how approaches are mixed based on our analysis of published IS AR studies, and the section that follows provides an overview of the 63 published papers in leading IS journals. Finally, we discuss the major findings and their implications for AR methodology and practice in IS research.

\section{THEORETICAL BACKGROUND}

Without a strong handle on how to design research approaches, researchers are unable to frame the research questions, analyse the data, develop and validate theory and inform science. Specifically, the research approach influences which conclusions can be drawn by shaping the explanation of the results. Each approach incorporates researcher beliefs, represents the ontology and epistemology of a field, and impacts how research contributes to and shapes scientific paradigms (van Fraassen, 1980; Salmon, 1989; Orlikowski \& Baroudi, 1991; Kinkaid, 1994; Hovorka et al., 2003). The identification and use of research approaches is therefore of primary importance both to the individual researcher and to the continued development of a discipline. 


\section{Action research}

$A R$ is a form of applied research that develops a solution to a practical problem, which is of value to the people with whom the researchers are working, while at the same time developing theoretical knowledge of value to a research community (Gustavsen, 1993; Levin, 1993; Kock et al., 1997; Davison, 1998, pp. 3-6; Coghlan, 2001). The dual outcome perspective states that AR is embedded within a practical context that is to be explained and changed. Within this context, an 'unstructured field experiment' takes place where researchers act as change agents to improve practical outcomes and describe new insights that result from the change (Baskerville \& Wood-Harper, 1998, p. 91).

AR links theory and practice often through a cyclical and often iterative process. There are many different ways to organize the cyclical process of AR (Baskerville \& Wood-Harper, 1998). The model of Susman \& Evered (1978) captures one approach that appears in a number of AR studies, called canonical AR (Davison et al., 2004). This canonical form includes one or more cycles of (1) diagnosing (identifying or defining a problem); (2) action planning (considering alternative courses of action for problem-solving); (3) action taking (selecting and executing a course of action); (4) evaluating (studying the consequences of the action); and (5) specifying learning (identifying general learning).

AR has been applied in IS for many years (Lau, 1997; Baskerville \& Wood-Harper, 1998). The method and purpose of its application has varied greatly, despite a common goal of uncovering both practical and theoretical knowledge. AR has contributed to many different areas of research within the IS discipline. Following Avgerou's (2000) classification of IS research, Table 1 shows select AR articles in leading IS journals. These cases represent the diversity of research areas to which AR has been applied.

While AR allows researchers to engage in practical problem-solving, it requires constant attention and specific skills to manage the dual objectives of both practical and theoretical

Table 1. AR studies in IS

\begin{tabular}{|c|c|c|}
\hline Classification & Illustrative articles & Research contribution \\
\hline $\begin{array}{l}\text { Organizational application } \\
\text { of information technology }\end{array}$ & $\begin{array}{l}\text { Davison \& Vogel (2000) } \\
\text { and Davison (2001) }\end{array}$ & $\begin{array}{l}\text { GSS was studied in a specific organizational } \\
\text { context leading to knowledge on GSS } \\
\text { adoption and use. }\end{array}$ \\
\hline $\begin{array}{l}\text { The process of } \\
\text { systems development }\end{array}$ & Baskerville \& Stage (1996) & $\begin{array}{l}\text { Risk analysis was shown to be an important } \\
\text { component in the prototyping of IS. }\end{array}$ \\
\hline IS management & $\begin{array}{l}\text { Mathiassen (2002) } \\
\text { and Mathiassen et al. (2002) }\end{array}$ & $\begin{array}{l}\text { Software practices were improved in four } \\
\text { organizations leading to knowledge on } \\
\text { software management. }\end{array}$ \\
\hline $\begin{array}{l}\text { The organizational } \\
\text { value of IS }\end{array}$ & Lindgren et al. (2003) & $\begin{array}{l}\text { The use of competency systems was } \\
\text { improved in a number of organizations } \\
\text { resulting in principles for quality design. }\end{array}$ \\
\hline The societal impact of IS & Wastell et al. (2004) & $\begin{array}{l}\text { This study explored how IS can be used to } \\
\text { reduce crime. }\end{array}$ \\
\hline
\end{tabular}

GSS, Group Support Systems. 
knowledge (Avison et al., 2001). Numerous dilemmas confront the researchers related to ethics, goals and initiative. These include lack of impartiality and methodological discipline leading to a form of reporting bias, goal dilemmas which collapse the study into consultancy and the potential context-dependency of results which may prevent generalization of findings (Baskerville \& Wood-Harper, 1998). For each dilemma, researchers need to constantly balance a concern for the practical problem and their research interests. Leaning too strongly towards practical concerns during the process will result in actions that are not theoretically informed and have little to contribute to IS theory. In the other extreme, leaning too strongly towards IS theory will result in actions that have little practical relevance for the specific setting. Avison et al. (2001) suggest that AR raises control issues related to the initiation of studies, the authority for action and the degree of formalization. They offer for each of these concerns a variety of approaches to help structure AR efforts. Others suggest that the careful and thoughtful mixing of research and problem-solving activities can also address these issues. We consider this next and discuss AR approaches used in published studies. Our analyses show that $A R$ is a dynamic approach to IS research that involves various mixings of problemresearch cycle activities and methods, driven by contributions to both theory and practice.

\section{Pluralism of cycles in AR}

McKay \& Marshall (2001) suggest that the success of an AR study in producing knowledge for both research and practice lies in the ability to inform both the research and the problemsolving cycles and manage the interaction between them. Attention to each cycle produces specific, different and complementary outcomes relevant to both cycles. The appropriate use and mixing of activities should help produce knowledge in both cycles, by applying theoretical knowledge in response to the practical problems at hand, and by using practical insights from actions taken in this problem setting, to discover new theoretical knowledge and inform future research. This general model of AR, in which knowledge is applied and discovered interactively between activities with different goals and outcomes, is summarized in Figure 1.

Figure 1. Problem-solving and research cycles in AR.

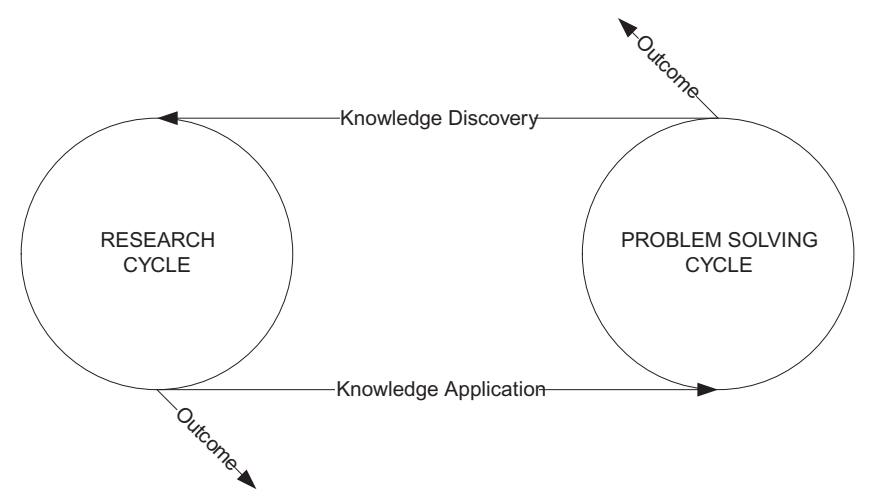


The research cycle is focused on research outcomes and the problem-solving cycle is focused on practical outcomes. Conceptually independent of one another, researchers engage in one or more research and problem-solving activities in these cycles, which are intrinsically related and often difficult to distinguish. However, by emphasizing the analytical separation between research and problem-solving cycles, McKay and Marshall provide a framework for investigating how knowledge is applied and discovered interactively between research and problem-solving activities. Other conceptions of AR describe the process through one cycle, e.g. as suggested by Susman \& Evered (1978) and Checkland et al. (1991). The cycle of Susman and Evered emphasizes both the research and practice domains through the specification of learning. Checkland distinguishes between two different outcomes from his proposed AR cycle: findings and action.

McKay and Marshall suggest transfer from problem-solving to research activities should be based on both applied and theoretical pragmatism, i.e. what worked in this setting and what could work elsewhere. Particularly, any theoretical knowledge discovered as a result of the production of a new artefact, solution or action in the problem setting should be noted in the research cycle as knowledge discovery. At the same time, any specific knowledge, currently unknown in the IS literature, which was useful in addressing the problem, should be considered in the research cycle as knowledge application. Through this, practice and research can both be informed through knowledge transfer between the two cycles.

\section{Pluralism of methods in AR}

On a more general level, Mingers (2001) offers two fundamental reasons for mixing research methods. First, the social world is multidimensional and includes the material, the personal and the social (Habermas, 1984). To address and understand these different aspects of the world, researchers may need a variety of research methods. Second, research is a process that involves rather different challenges and activities, which will predominate at different times as the research process unfolds. To effectively address the challenges - including the appreciation of the research situation, the analysis of data, the assessment of explanations, the conduct and reporting of action and the dissemination of results - the researcher may need different methods. Particularly, as researchers move through material, personal and social perspectives (Habermas, 1984), and as they take part in appreciation, analysis, assessment and action during the research process, they are advised to adopt research methods from different epistemological perspectives which support a movement from appreciation to action. In doing so, they mix multiple methods in order to shape study-specific approaches to examine and explain research phenomena.

Mingers (2001) addresses this thinking through five different types of multi-method research approaches: sequential where research methods are applied in a sequence with the results from one method feeding into the next; paralle/ where research methods are executed simultaneously with results being transferred between them; dominant where one research method is adopted as the main approach supplemented by other methods; multi-methodology where 
different research methods embodying different paradigms are combined and tailored to a particular programme; and multi-level where the research addresses different organizational levels using different methods.

Mixing research methods requires, in each of these cases, certain skills to effectively manage the additional complexity involved in multi-method research. Researchers must know how to organize and manage the appreciation, analysis, assessment, reporting and dissemination activities by selecting and mixing research methods. One method may describe a research setting, illustrate the context of the research (Checkland, 1981) and lay out the researcher's relationship to the setting, thus informing their use of other methods. Other research methods can address research questions that arise from the use of the first method. This in turn forms an aggregate research programme that provides greater comprehension of the phenomenon.

From the specific perspective of IS AR, there is an additional motivation and need to apply multiple methods. Action researchers, like other IS researchers, study multidimensional phenomena and they need to manage complex and diverse research processes. However, somewhat unique to $A R$ is that the researcher creates theoretical and practical knowledge in responding to both research and practical goals in a specific context (Rapoport, 1970). Action researchers are therefore faced with the challenge of mixing research methods in order to create both practical and theoretical contributions.

\section{RESEARCH METHOD}

Stemming from the use of AR in IS and methodological pluralism, our research addresses the following two research questions.

Research Question 1: How are research and problem-solving activities mixed within each individual IS AR study?

Research Question 2: How are research methods mixed in the wider research programmes in which IS AR studies are situated?

In response to these questions, we conducted a systematic review of published AR studies in leading IS journals following the guidelines suggested by Webster \& Watson (2002).

\section{Selection of articles}

Articles were chosen to be representative of the published IS AR. The literature survey, which covered research articles from 1982 to 2005, was conducted through searches in the EuclidPLUS library catalogue and research databases, including CiteSeer ABI/Inform and covering journals in the IS discipline. We focused on articles published in leading journals identified from IS World's journal list (http://www.isworld.org/csaunders/rankings.htm). We included journals that were ranked on the list, which were focused on traditional IS research topics, and which 
were likely to publish some AR work. We also included articles to be representative of AR across the world, representing seventeen countries from North America, Europe, Asia and Australia.

Articles identified included those that had the phrase action research in the title, abstract, keyword or body of the article. From the large number of articles that met this criterion, we then identified those articles that used AR as a method in a field study, by examining the research methods sections. We included any article that identified AR as one of their methods. In all, we identified $63 \mathrm{AR}$ articles as a basis for the review (Appendix).

\section{Analysis of articles}

Reviewing the articles, we developed two frameworks that characterize how methods are mixed in IS AR studies: (1) the research dominant, problem-solving dominant and interactive approaches to sharing of knowledge across research and problem-solving cycles; and (2) the dominant and sequential approaches to mixing of AR with other research methods. The frameworks were developed through a dialectical process (Mason, 2004) of iteratively applying concepts from IS and AR methodology studies (i.e. McKay \& Marshall, 2001; Mingers 2001) to the 63 AR studies published in leading IS journals. As a result, our frameworks were informed by existing theory and can, in that sense, be seen as expressions of deductive reasoning (Mason, 2004) in which 'theory comes first' and the movement is from the general towards the particular. On the other hand, our frameworks were also the result of analysing particular material, i.e. the 63 published IS AR studies, and our frameworks emerged, in that sense, through inductive reasoning (Mason, 2004) in which 'theory comes last' and the movement is from the particular to the general.

As a part of this dialectical approach, we used the two frameworks to systematically code each of the 63 articles. Two authors coded the entire set of articles to determine relevancy and consistency. If inconsistency was still evident between the two coders, the third author was brought in to mediate so that $100 \%$ agreement was achieved for every article between the two coders. In all, no more than $10 \%$ of the articles required third party mediation (i.e. approximately $90 \%$ consistency between coders). Our approach did not lend itself to the calculation of Cohen's Kappa as we focused on complete coding agreement between the coders on every article. The coding process itself required a full text read of the articles focusing on the presentation of the research method, the research cycle, the problem-solving cycle, and how the two were mixed. We also captured the number of AR cycle implementations, the research and practical findings, and justifications for our coding.

To decide how research and problem-solving activities were mixed, we focused on the individual AR study described in each paper. We analysed how problem-solving activities were executed in each study and how they were influenced by theoretical knowledge, or how theoretical knowledge was discovered based on project and setting-specific findings. We then summarized the mixing of activities into research dominant, problem-solving dominant or interactive based on the dominant approach in the text. For example, if the emphasis in the presented AR study was predominantly on theoretical knowledge leading into the selection of 
problem settings to validate theory, we coded it as research cycle dominant. If the emphasis was on problem-solving techniques and outcomes with subsequent discovery of new theoretical knowledge, we coded it as problem-solving dominant. Finally, if the AR study was mainly based on interacting or overlapping research and problem-solving activities, we considered it to be interactive.

To decide how research methods were mixed in each article, we focused on the wider research programme in which each AR study was situated. Information about this wider context was generated directly from the presented research approach in each paper, or indirectly by considering references to other publications by the same group of authors in each paper. For example, if the article was not related directly to previous work by the authors, we coded it as dominant. If the article was a follow-up on previous studies, we coded it as sequential.

\section{PLURALIST APPROACHES}

In the following section, we provide an account of how research and problem-solving activities and research methods are mixed in IS AR studies with illustrative examples from the reviewed articles. In the next section, we provide a summary of how the 63 articles mix research methods and activities across the two cycles. We then discuss the implications of our findings for AR methodology and practice.

\section{Mixing research and problem-solving activities}

Research dominant, problem-solving dominant and interactive reflects diverse ways in which action researchers emphasize the research and problem-solving activities in their study and the transfer of knowledge between the two cycles of AR (McKay \& Marshall, 2001). In the following, we define each of these approaches and provide examples of how they are adopted in IS AR.

\section{Research dominant}

The research dominant approach (Figure 2) emphasizes research activities at the outset, by focusing on theoretical ideas that could inform one or more problem-solving situations. The research activities are used to inform and shape the problem-solving activities within specified classes of problems and settings. In focusing on research activities at the outset, the problem setting is considered representative of a class of problems that could be informed by current IS theory. As a result, problem-solving activities are used to confirm or disconfirm the applicability of theoretical knowledge to a practical problem setting.

As an example, Baskerville \& Stage (1996) invoke research activities to specify a theoretical approach to risk-based prototyping, and then use this approach in the development of a system in a specific setting. In this case, IS theory informs the problem-solving methods, which 


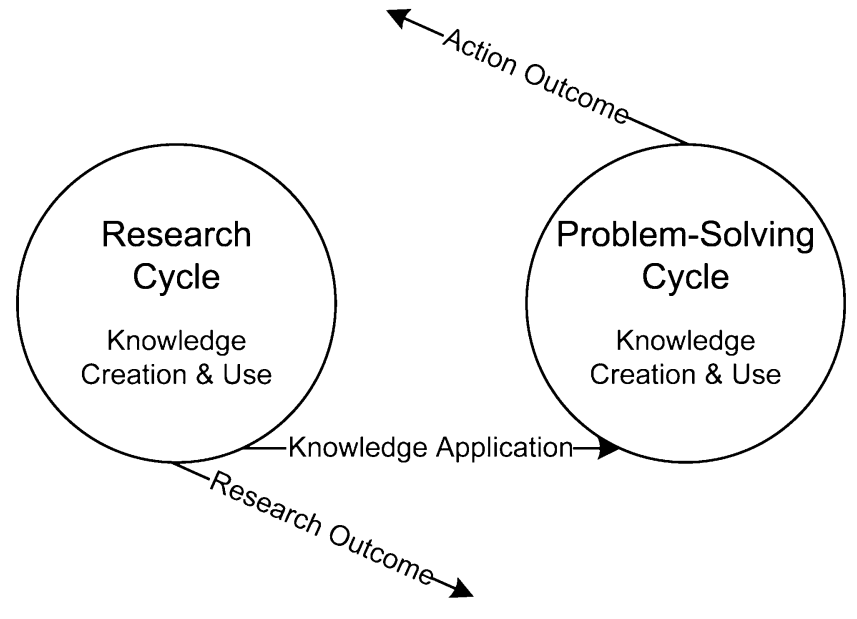

Figure 2. Research dominant mixing of activities.

are then used to develop a successful prototype in a not-for-profit setting. The article is a research dominant mixing of research and problem-solving activities because the theory that emerges from early-stage research activities are used to guide the selection of sites, problems and particular development methods. The successful development of the software during problem-solving activities is initial confirmation of the relevance of the theoretical knowledge identified in the early-stage research activities.

\section{Problem-solving dominant}

The problem-solving dominant approach (Figure 3) to mixing research and problem-solving activities focuses predominantly on the generation and analysis of findings from problemsolving activities that emerged during a study. After the problem is solved, insights and data from the problem-solving activities are used to compare and contrast with existing knowledge, or to develop new theoretical knowledge in later-stage research activities. In many ways, problem-solving dominant approaches to mixing research and problem-solving activities are like a grounded-theoretical approach to AR, which emphasizes the participants' own ability and expertise, including the researchers', to address setting-specific issues.

As an example, Burstein \& Linger (2003) analyse seven cases of knowledge management systems implementation. Their grounded theoretical approach identifies important findings and themes from the successful development of knowledge management systems, which includes a focus on specific tasks incorporating both knowledge structures and processes (p. 302). The analysis of their problem-focused activities provides important and grounded findings that allows for the development of IS theory in later-stage research activities. As a result, research activities are invoked to understand the findings produced during the study. 
Figure 3. Problem-solving dominant mixing of activities.

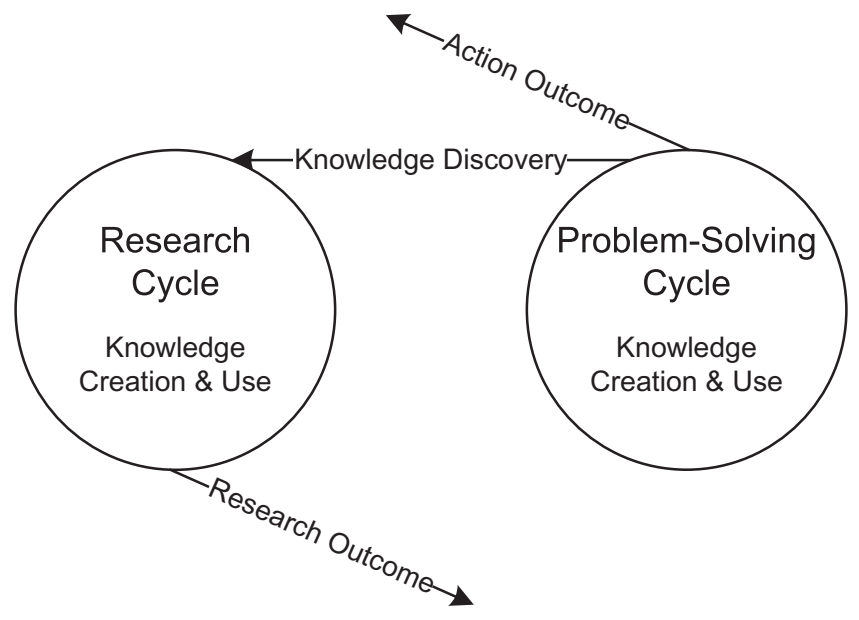

Figure 4. Interactive mixing of activities.

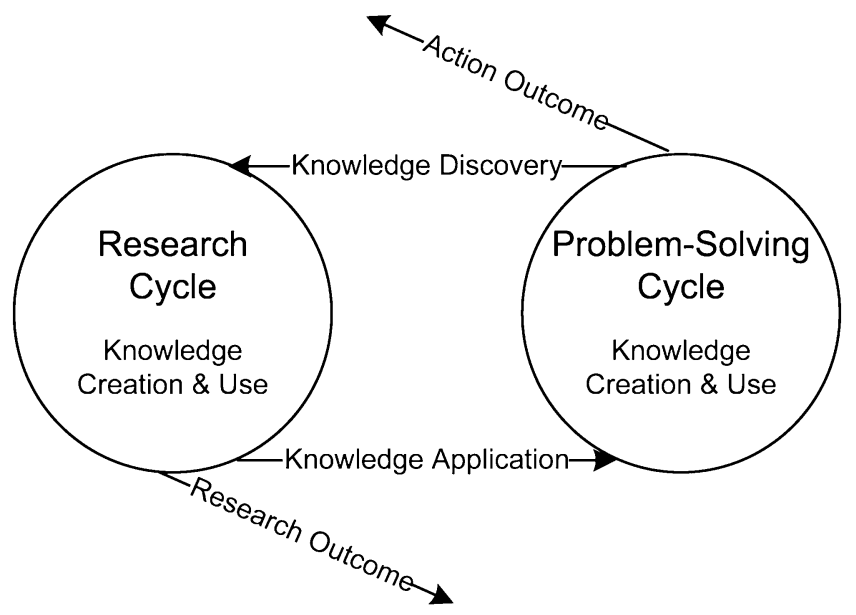

\section{Interactive}

The interactive approach (Figure 4) invokes research and problem-solving activities at various stages throughout the study, in order to inform and support each cycle. As a consequence, theoretical knowledge from the research cycle is applied in the problem-solving cycle, and findings from the problem-solving cycle influence the midstream research activities in attempts to discover new theoretical knowledge. While the two cycles have distinct goals and involve unique activities, they are mutually dependent as ideas and findings are transferred back and forth between them throughout the study.

As an example, Chiasson \& Dexter (2001) explore why the IS prototyping approach to AR failed to resolve structural conflict in the development of a hospital patient record system. The 
study considers various theories concerning IS prototyping and its failure to successfully implement a system in this particular case. This included whether certain prototyping stages were ignored by the developers, or whether prototyping is ineffective in settings with severe structural conflict. Once the structural conflict was removed through organizational change in further problem-solving activities, a prototype was successfully implemented. Kohli \& Kettinger (2004) also consider the development of an information system in a healthcare setting, in this case, a physician profiling system to control hospital costs. After a failed implementation of this decision support system to monitor physicians, the authors report an alternative approach to system implementation shaped by concepts from agency theory, called 'informating the clan'. This approach allows the physicians to monitor themselves, and a revised decision support system was implemented.

\section{Mixing research methods}

We identified two main approaches to mixing AR with other research methods in the literature: the dominant and the sequential approaches. These approaches represent different ways in which IS researchers structure the use of AR methods in their study.

\section{The dominant approach}

In the dominant approach, researchers use an AR method from the outset and use other research methods to examine and explain research questions. AR is chosen and articulated as a primary method of investigation from the very start of the research programme, and it is thus a key part of the research process for producing explanations.

Mathiassen et al. used a dominant approach to AR to study software process improvement in four software companies over a 3-year period (Mathiassen, 2002; Mathiassen et al., 2002) with additional methods used in sequence. The dual purpose of this programme was to improve software practices in four software organizations and at the same time to contribute to knowledge on software management. Half a dozen researchers and nearly 40 practitioners participated and the programme resulted in a number of contributions, including a book (Mathiassen et al., 2002), three PhD dissertations and more than 30 conference and journal articles. A few, selected publications illustrate how different research methods were adopted and mixed in this dominant approach to AR (Figure 5). This dominant AR programme exemplifies a research design in which specific software practices were studied and reported on multiple levels of analysis based on a portfolio of research methods including literature surveys, case studies, field experiments and focused AR efforts (Mathiassen, 2002).

Mathiassen et al. (2002) documents the dominant application of AR in the four organizations. The book includes key lessons from each of the four software organizations together with contributions that focus on specific issues, e.g. assessment of software practices, adoption of knowledge management tactics in software process improvement and practical approaches to process implementation. The book presents contributions from the overall programme based on AR. Aaen et al. (2001) offer a conceptual framework for understanding software process 


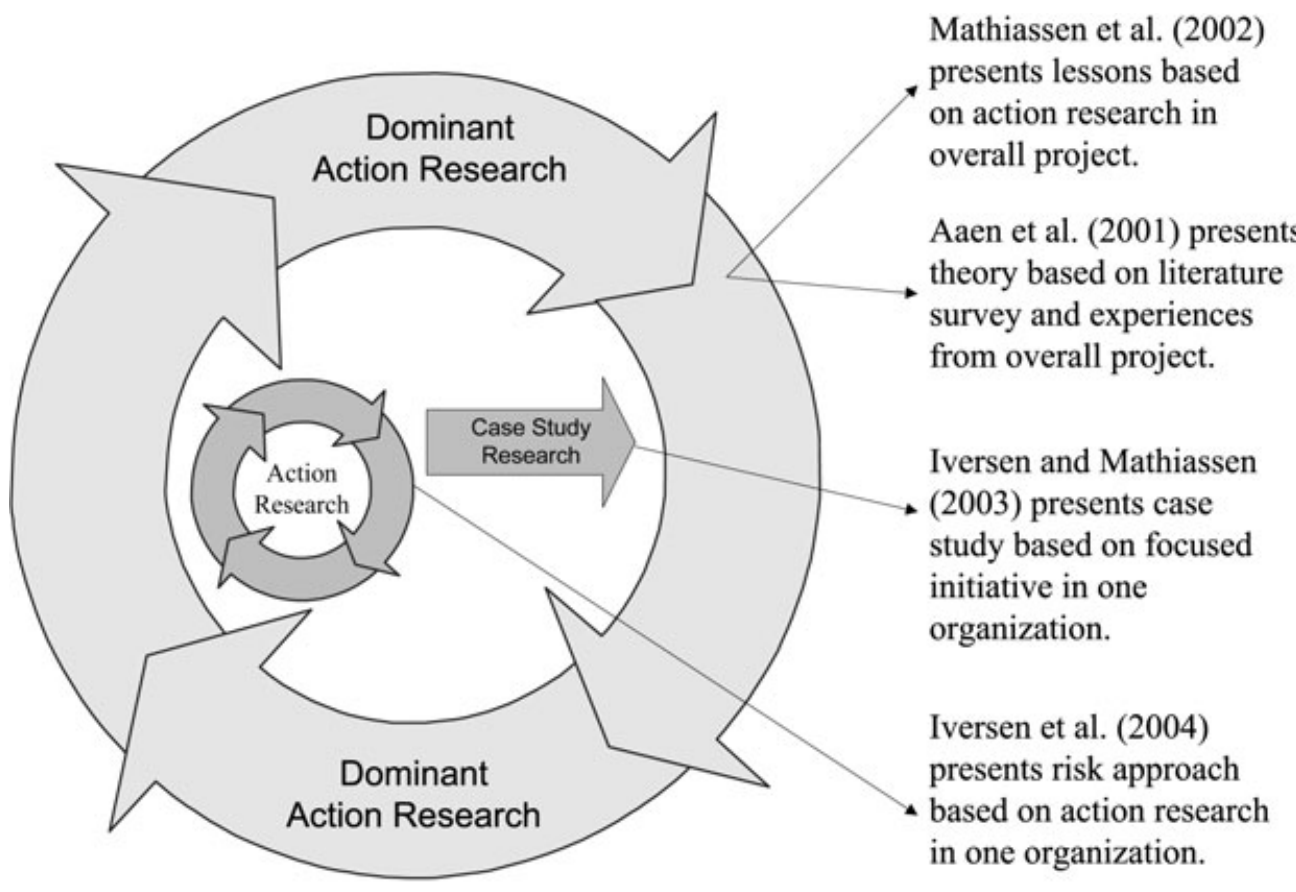

Figure 5. A dominant approach to AR.

improvement theory and for assessing strategies adopted by specific organizations. The software process improvement domain is broad with little agreement on the underlying assumptions and key ideas involved to improving software practices. Aaen et al. (2001) provide a conceptual framework based on a systematic survey of the software process improvement literature and informed by experiences from the four organizations. This publication represents theory development from the programme based on studies of software process improvement practices in the four organizations.

Other publications were developed based on focused activities within the larger programme. These publications emphasize particular issues related to software process improvement, drawing upon incidents in one or more of the four organizations, and adopting a variety of theoretical frames and research approaches. They also represent the sequential and multi-methodology approaches of Mingers (2001). Two examples illustrate this. Iversen \& Mathiassen (2003) present a traditional case study based on interviews, documents and minutes of meetings in an attempt to design and implement a software metrics programme in one of the four organizations. AR played no role in the development of this particular publication, but the AR approach to the overall programme created the opportunity for the involved researchers to identify and develop this research. In contrast, Iversen et al. (2004) present an approach to manage the risks of software process improvement studies. The risk management 
approach was developed in response to specific needs in one of the four software organizations. The opportunity to engage in this particular effort was again created by the overall AR approach. This time the researchers adopted AR for the specific, focused activity.

\section{The sequential approach}

In the sequential approach, researchers adopt AR as a complementary method that is helpful for additional examination and explanation of the research phenomena as the research programme unfolds (Mingers, 2001). In these cases, AR is used later in a series of interrelated studies to validate or further develop theoretical findings by applying them to specific problem settings.

Markus et al. (2002) represents an example of a sequential approach to IS AR. Their research is a response to a call for design theories in the context of executive IS (Walls et al., 1992). The design of such systems is comprised of a set of requirements to address a class of problems, a description of artefacts to meet those requirements, kernel theories from the natural and social sciences and a set of hypotheses that can be used to verify whether the design satisfies the requirements. Markus et al. (2002) used AR to develop a design theory for emergent knowledge systems. In doing so, they followed an iterative process of specifying kernel theory, developing hypotheses, implementing in-use systems and integrating findings back into the development of new theory. As illustrated in Figure 6, these activities are embedded within an overarching research programme including a sequence of publications (i.e. Majchrzak \& Finley, 1995; Majchrzak, 1997; Majchrzak \& Gasser, 2000). The overall research programme involved a variety of methods (field observation, case study and AR) to help understand, explain and design sequential knowledge systems. Hence, the use of AR emerged as part of a larger research programme and was used in sequence with other research methods rather than as a dominant method from the outset. The resulting design theory could potentially be further validated, refined and adopted towards other domains. Such explorations would continue the sequential process and further develop the theory through field experiments, case studies or renewed AR efforts.

The dominant and sequential approaches represent two different, yet complementary, ways in which AR is mixed with other research methods in IS studies. In these cases, findings are

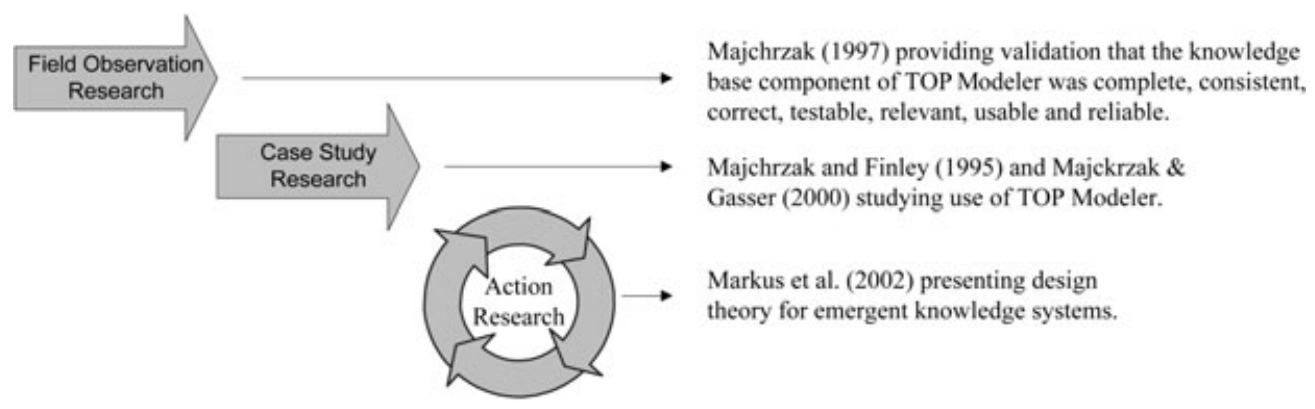

Figure 6. A sequential approach to AR. 
constructed and debated from an existing domain of knowledge (Latour, 1987). If the findings are relevant they can be re-examined in light of new methods and tools as well as being subjected to questions of authenticity and research trends. From Latour's perspective, Mathiassen et al. (2002) used AR in a dominant approach to contribute a new framework to an existing domain of knowledge. Based on the relevancy of the Mathiassen et al. framework, subsequent studies ensued, relying on additional methods in an sequential approach to further examine earlier software process improvement findings in the particular context of a metrics programme (Iversen \& Mathiassen, 2003) and software process improvement risk management (Iversen et al., 2004). In summary, the dominant use of AR from the outset is considered the key method in carrying out a research programme. The sequential use of AR appears during the unfolding of a research programme and is conceived to respond to new research questions that arise.

At the same time, the dominant and sequential approaches are different as the dominant approach offers an explicit way to adopt, organize and manage Mingers' (2001) framework for multi-method research. Appreciation, analysis, assessment and action are easily adopted and enacted through the AR cycle activities of diagnosing, action planning, action taking, action evaluation and the specifying of learning (Susman \& Evered, 1978). In contrast, the sequential approach offers few explicit ways to enact Mingers' activities across the larger research agenda. Instead, Mingers' framework can be used to reflect on and manage the process as it unfolds.

\section{RESULTS}

Applying the previous concepts to each of the 63 AR articles, we arrived at various patterns of mixing methods in IS AR. These patterns show how action researchers mix methods in order to successfully publish their work. Full representation of all articles with an explanation of the adopted coding is available at http://people.uwec.edu/germonr/PluralistActionResearch.pdf.

In Table 2 we summarized how methods and activities are mixed across IS journals. We have listed the journals in order of how many AR articles were published during the considered period, i.e. from 1982 to 2005, and for each journal we have listed how the articles mixed research and problem-solving activities within a study as well as mixing research methods across a research programme. Despite the small numbers, the summary offers a number of interesting insights into AR practices within IS. First, most AR studies are published in only a handful of journals; 51 out of the 63 articles or $80 \%$ are published in ITP, Information Systems Journal (ISJ), MISQ, European Journal of Information Systems (EJIS) or Information and Organization (I\&O). Also, it is worth noting that for two of these journals, ITP and MISQ, a portion of the articles ( 3 and 6 ) were published in a special issue on AR. Other leading IS journals account for only a minor portion $(20 \%)$ of published AR studies. Second, there is a fair representation of all three forms of mixing research and problem-solving activities across the reviewed articles. This suggests that AR is understood as a methodology that provides the researcher with a variety of options for adoption in specific research contexts. However, it is interesting to note that a large percentage of studies use problem-solving dominant 
Table 2. Pluralist approaches to AR across IS journals

\begin{tabular}{lcccccc}
\hline Journal & $\begin{array}{c}\text { Research } \\
\text { dominant }\end{array}$ & $\begin{array}{c}\text { Problem-solving } \\
\text { dominant }\end{array}$ & Interactive & Dominant & Sequential & Total \\
\hline ITP & 3 & 6 & 7 & 7 & 9 & 16 \\
ISJ & 2 & 6 & 3 & 3 & 8 & 11 \\
MISQ & 5 & 2 & 3 & 4 & 6 & 10 \\
EJIS & 2 & 3 & 2 & 3 & 4 & 7 \\
I\&O & 1 & 5 & 1 & 1 & 6 & 7 \\
Data Base & 1 & 2 & 2 & 2 & 3 & 5 \\
I\&M & 2 & 1 & 1 & 2 & 3 & 4 \\
JMIS & 1 & 0 & 0 & 0 & 0 & 3 \\
ISR & 0 & 0 & 0 & 0 & 0 & 0 \\
JAIS & 0 & 27 & 19 & 25 & 38 & 0 \\
Total & 17 & 2 & 0 & 3 \\
\hline
\end{tabular}

ISR, Information Systems Research; JMIS, Journal of Management Information Systems; JAIS, Journal of the Association for Information Systems.

Table 3. Pluralist approaches to action research across years

\begin{tabular}{|c|c|c|c|c|c|c|c|c|}
\hline Year & $\begin{array}{l}\text { Research } \\
\text { dominant }\end{array}$ & $\begin{array}{c}\text { Problem-solving } \\
\text { dominant }\end{array}$ & Interactive & Dominant & Sequential & Total & $\begin{array}{c}\text { Total number } \\
\text { of articles }\end{array}$ & $\begin{array}{c}\% \text { of } \mathrm{AR} \\
\text { studies }\end{array}$ \\
\hline 1982-1985 & 1 & 0 & 0 & 0 & 1 & 1 & 261 & 0.38 \\
\hline 1986-1989 & 0 & 0 & 0 & 0 & 0 & 0 & 493 & 0.00 \\
\hline 1990-1993 & 1 & 1 & 0 & 2 & 0 & 2 & 659 & 0.30 \\
\hline 1994-1997 & 2 & 4 & 3 & 1 & 8 & 9 & 769 & 1.17 \\
\hline 1998-2001 & 6 & 10 & 7 & 9 & 14 & 23 & 845 & 2.72 \\
\hline 2002-2005 & 7 & 12 & 9 & 13 & 15 & 28 & 987 & 2.86 \\
\hline Total & 17 & 27 & 19 & 25 & 38 & 63 & 4014 & 1.57 \\
\hline
\end{tabular}

approaches to AR (27 out of the 63 or $43 \%$ ), and many of these appear in journals amenable to interpretive work (ITP, ISJ and I\&O). The numbers also suggest that the sequential approach is used more often in AR than the dominant approach, and these studies are also published in journals more amenable to interpretive work. Third, a significant portion of the published AR studies are sequential (38 out of 63 or $60 \%$ ). This suggests that IS researchers often mix AR with other research methods as part of their evolving research programmes. These researchers initiate studies using a variety of research methods, and then adopt AR to further develop insights in a practical problem setting.

In Table 3 we summarized the results chronologically across the period 1982 to 2005. There has been a dramatic increase in the number of AR articles across all categorizations. The last 3 years of investigated research has accounted for $45 \%$ of AR studies published in leading IS journals. This trend may be the result of researchers responding to the pressures to contribute both to research and practitioner communities. As grant monies increase from private organizations and governments, studies may need to appeal to specific practices more than they 
did in the past. It may also be the result of various attempts and desires by IS academics to link theory and practice together in addressing a perceived crisis of relevance. Finally, AR studies may also have been published in books and other outlets besides journals in the past. Given the increasing use of AR in IS, journal editors and reviewers may have become more versant and interested in AR work.

It is also important to see the increasing use of AR as a dominant method in research in the last 6 years. This suggests that more researchers are considering AR at the outset of their research programmes, possibly due to its increased legitimacy in the field and its ability to encompass multi-method approaches to research. We consider some of the broader discussion topics next.

\section{DISCUSSION}

We analysed AR studies published in leading IS journals from 1982 to 2005 . Our focus was on how research and problem-solving activities (McKay \& Marshall, 2001) and how research methods (Mingers, 2001) are mixed to apply and discover knowledge in these studies. Our analysis has led to a conceptual understanding of how action researchers conduct and publish their work across leading IS journals.

\section{Mixing research and problem-solving activities}

In response to Research Question 1, we identified three ways in which IS action researchers mix research and problem-solving activities. Given that all three approaches were fairly well represented (see Table 2), our research suggests that IS researchers see AR as a methodology that can be adopted in a variety of ways to manage the various risks of $A R$, especially the dual goals of practical problem-solving and theoretical development.

First, AR is sometimes conducted in a way that meets traditional expectations of research by being research dominant. This approach allows the researcher to focus on research activities at the outset, identifying IS theory relevant to practice before entering a problem setting. In this way, study selection and problem-focus is guided by IS theory to produce relevant scientific knowledge. This approach is especially beneficial when theory needs to be validated and extended to ensure its applicability to practice. However, action researchers driven by research activities could colonize a problem setting by using IS theories that the researchers wish to confirm, without due attention to setting-specific issues. To avoid this problem, researchers can either pull out of a problem situation when the IS theory is no longer relevant, or they can adopt more interactive approaches to knowledge sharing that would allow them to draw upon other IS theories given changes in the problem setting.

Second, some AR studies emphasize the practical problem and its appropriate solution by adopting a problem-solving dominant approach. These studies represent an applied approach to research that can productively challenge extant IS theory and traditional approaches to IS research, driven predominantly by the research cycle and IS theory. This approach is especially beneficial for new and extreme cases in which the researcher seeks to discover new 
theory arising from the problem setting. However, problem-solving dominant approaches also increase the risk that the research collapses into consultancy without a clear research direction and contribution. This risk can be addressed by identifying theoretical areas of concern at the earliest possible time to allow study findings to contribute to theory (Checkland \& Holwell, 1998). Also, it can be addressed by systematically applying criteria for good AR to the study (Davison \& Martinsons, 2007). Finally, consistent with traditional approaches to research, it may be beneficial to follow-up on a problem-solving dominant study with a research dominant study to validate the initial and exploratory knowledge.

Third, there are cases with an equal emphasis on research and problem-solving activities adopting an interactive approach to AR. In these studies, the researcher offers separate discussions of the research and problem-solving activities at various points in the article, with knowledge being applied and discovered across cycles. While interactive approaches may represent an ideal form of $A R$ in which both theory and practical findings inform each other, they are often long and difficult to report in a single paper. In some cases, it is hard to discern precisely how knowledge is exchanged across activities as a plethora of ideas from theory and findings from practice are being considered and reported throughout the article. A detailed account of the study is achieved by clearly distinguishing between occurrence of research and problem-solving activities and by differentiating clearly between contributions to research and practice. Researchers should consider a research diary or log of daily activities in the research study (Jepsen et al., 1989). Such an approach can provide causal understanding in the balanced act of managing the research and problem-solving cycles concurrently.

Considering the potential of AR to create synergy by applying and exchanging knowledge between practice and theory, it is somewhat surprising that only a minority of the studies (31\%) are based on an explicit interaction between the research and problem-solving cycles. Considering also how the adoption of the three approaches is distributed over the period 1982 to 2005 , we have seen marked increases in the problem-solving dominant approaches. Reasons may include the following:

1 the need for more applied research in our discipline based on corporate and government grants that require product development;

2 the integration of academic disciplines in IS research that rely on the development of products;

3 tenure and promotion pressures that push both academic and practice implications of research and hence require a stronger balance between rigour and relevance; and

4 an increase in non-experimental work within organizations that are designing, developing and implementing systems requiring researchers to service the organizations through problem-solving while still maintaining an academic emphasis on research interests.

\section{Mixing research methods}

In response to Research Question 2, our research shows that IS action researchers use multiple research methods to study complex phenomena and to create multiple research 
contributions from each programme of research. While Mingers (2001) emphasizes pluralist approaches to study multi-dimensional phenomena, he implicitly assumes that a research process and outcome result in only one publication. There is, as we have seen in many published IS AR studies, the possibility that a single research programme could produce several published outcomes. In some cases, each publication is based on different combinations of research methods practised within an AR frame. In others, AR is used as a separate method within a series of studies to validate and develop theoretical ideas based on previous findings.

Our analysis identified dominant and sequential approaches as two different yet complementary ways to use AR to develop practical and theoretical knowledge. The two approaches differ in that the dominant approach adopts an AR method from the outset, in combination with other methods (Mingers, 2001). Using this dominant approach, the appreciation, analysis and assessment of action are considered from the outset, with other methods used within or in combination with AR to assist in diagnosis, action planning, action taking, evaluation and the specification of learning (Susman \& Evered, 1978). In the sequential approach, AR methods are considered as new research questions and possibilities emerge from the initial research. In this case, Mingers' framework can be used to reflect on the sequential and parallel use of AR methods as a research programme unfolds. Interestingly, a majority of the studies (60\%) adopted a sequential approach to AR (see Table 2), indicating that IS researchers find AR a useful, complementary method after research insights are achieved through other methods, as a way to confirm and further develop their ideas. However, dominant approaches to AR have increased considerably in the past 6 years, perhaps because the use of and confirmation of knowledge through action is now being considered from the outset of IS studies.

Given these findings, IS action researchers combine research and practical problem-solving activities to develop contributions to IS research and practice by discovering and validating theoretical knowledge within a specific problem setting. This ability to develop contributions relevant to many settings while at the same time solving practical problems in a particular setting requires a delicate and creative balance in which different kinds of methods and activities are mixed. The two different approaches to mixing AR methods with other research methods and the three different approaches to mixing research and problem-solving activities represent the strategies through which IS action researchers have implemented AR as presented in the literature.

\section{Limitations and implications}

Before considering the implications of our work for IS AR, our study has a number of limitations. Our focus on mixing methods and activities and our choice of codes for AR studies are only a few among many that could have been chosen. Additional research is required to expand the range of viewpoints in studying AR practices within our field. There were also challenges in coding articles into only one category among the dominant/sequential and the research/problem-solving/interactive codes. The coding depended on our interpretation of the 
predominant emphasis by the authors in their research portrayal to determine whether their work was either dominant or sequential, and either research dominant, problem-solving dominant or interactive. Although several authors were contacted to validate our interpretations, further work is required. Such work includes using interviews and perhaps observations to study the actual day-to-day process of planning and executing AR and the mixing of methods and activities during AR. Finally, by focusing on published articles, our study follows the arbitrary cut-off points selected by action researchers. We have tried to compensate for this by exploring dominant and sequential approaches to AR considering the wider research programmes in which AR studies are situated. Further research will need to combine insights from planning, organizing and managing programmes (e.g. Avison et al., 2001; McKay \& Marshall, 2001 ) with varied research methodologies in order to address these limitations. We also did not consider the important issue of which specific research methods and their application are consistent with AR epistemology and practices. Additional research could investigate in detail which specific research methods and their implementations are mixed with AR within the same research programme. Such studies could also discuss the complex epistemological issues related to mixing AR with other research methods. Finally, our study neglected issues of power and domination in problem formulation and resolution in IS AR. For example, we did not consider which groups and individuals construct and raise problems in a particular setting and how this maintains or disrupts organizational power. Future research and philosophical discussion will be required to understand and appreciate how power and domination are handled in IS AR.

Despite these limitations, the study offers important insights for those practising and wishing to practise AR in IS. AR lends itself to the unique and valuable mixing of methods and activities in addressing both research and practical goals in the field. Regardless of the approach, the sense of pragmatism is prevalent in AR, in considering what works in a specific setting and how the knowledge from a specific setting could be useful in other settings. For researchers writing AR studies and for reviewers evaluating AR studies, these insights suggest that articles should present the adopted pragmatism more explicitly by documenting the reasons why types of research activities (research and problem-solving) and types of research methods (AR and others) are mixed in specific ways.

In focusing on the pragmatic use of and generation of knowledge, AR uses various approaches to mixing research and problem-solving activities. Each offers various benefits and challenges for the researcher. The research dominant approach focuses on theoretical ideas and concepts that could help practice, and applies these in settings that could benefit from these concepts. In this way, the research dominant approach to AR focuses on what has worked elsewhere and shows how it can be applicable in new settings. The problem-solving dominant approach, on the other hand, focuses on what has worked in a particular problem setting and considers whether such experiences could be useful in other settings. In this case, the pragmatic process is reversed - what has worked here, could work elsewhere. The interactive approach addresses both the 'what has worked here' and the 'what has worked elsewhere' questions through a process of selection, trial-and-error and interactive exchange of knowledge between the research and problem-solving cycles. 


\section{REFERENCES}

Aaen, I., Arent, J., Mathiassen, L. \& Ngwenyama, O. (2001) A conceptual map of software process improvement. Scandinavian Journal of Information Systems, 13, 123-146.

Avgerou, C. (2000) Information systems: what sort of science is it? Omega, 28, 567-579.

Avison, D., Baskerville, R. \& Myers, M. (2001) Controlling action research projects. Information Technology \& People, 14, 28-45.

Baskerville, R. \& Stage, J. (1996) Controlling prototype development through risk analysis. MIS Quarterly, 20, 481-504.

Baskerville, R. \& Wood-Harper, T. (1996) A critical perspective on action research as a method for information systems research. Journal of Information Technology, 11, 235-246.

Baskerville, R. \& Wood-Harper, T. (1998) Diversity in information systems action research methods. European Journal of Information Systems, 7, 90-107.

Burstein, F. \& Linger, H. (2003) Supporting post-Fordist work practices: a knowledge management framework for dynamic intelligent decision support. Journal of Information Technology and People, 16, 289-305.

Checkland, P. (1981) Systems Thinking, Systems Practice. John Wiley \& Sons, Chichester, UK.

Checkland, P. (1991) From framework through experience to learning: the essential nature of action research. In: Information Systems Research: Contemporary Approaches and Emergent Traditions, Nissen, H.E. et al. (eds), pp. 397-403. Elsevier, North-Holland, The Netherlands.

Checkland, P. \& Holwell, S. (1998) Action research: its nature and validity. Systemic Practice and Action Research, 11, 9-21.

Chiasson, M. \& Dexter, A. (2001) Systems development conflict during the use of an information systems prototyping method of action research: implications for practice. Information Technology \& People, 14, 91-108.

Coghlan, D. (2001) Insider action research projects: implications for practicing managers. Management Learning, 32, 49-60.

Davison, R. (1998) An action research perspective of group support systems: how to improve meetings in Hong Kong. PhD dissertation, City University of Hong Kong. [WWW document]. URL http://www.is.cityu. edu.hk/staff/isrobert/phd/phd.htm (last accessed 20 February 2008).
Davison, R. (2001) GSS and action research in the Hong Kong police force. Information Technology and People, 14, 60-77.

Davison, R.M. \& Martinsons, M.G. (2007) Action research and consulting: hellish partnership or heavenly marriage? In: Information Systems Action Research: An Applied View of Emerging Concepts and Methods, Kock, N.F. (ed.), pp. 377-394. Springer Verlag, Berlin, Germany.

Davison, R. \& Vogel, D. (2000) Group support systems in Hong Kong: an action research project. Information Systems Journal, 10, 3-20.

Davison, R., Martinsons, M. \& Kock, N. (2004) Principles of canonical action research. Information Systems Journal, 14, 65-86.

van Fraassen, B. (1980) The Scientific Image. Oxford University Press, Oxford, UK.

Gustavsen, B. (1993) Action research and the generation of knowledge. Human Relations, 46, 1361-1365.

Habermas, J. (1981) The Theory of Communicative Action. Beacon Press, London.

Habermas, J. (1984) The Theory of Communicative Action Vol. 1: Reason and the Rationalization of Society. Heineman, London.

Hovorka, D., Germonprez, M. \& Larsen, K. (2003) Explanation in information systems. Sprouts: Working Papers on Information Environments Systems and Organizations, 3, 169-187.

Hovorka, D., Germonprez, M. \& Larsen, K. (2008) Explanation in Information Systems. Information Systems Journal, 18, 23-43.

Iversen, J. \& Mathiassen, L. (2003) Cultivation and engineering of a software metrics program. Information Systems Journal, 13, 3-19.

Iversen, J., Mathiassen, L. \& Nielsen, P.A. (2004) Managing risks in software process improvement: an action research approach. MIS Quarterly, 28, 395-433.

Jepsen, L., Mathiassen, L. \& Nielsen, P.A. (1989) Back to thinking mode-diaries as a medium for effective management of information systems development. Behaviour and Information Technology, 8, 207-217.

Kinkaid, H. (1994) Assessing functional explanations in the social sciences. In: Readings in the Philosophy of Social Science, Maratin, M. (ed.), pp. 341-354. MIT Press, Cambridge, MA, USA.

Kock, N., McQueen, R. \& Scott, J. (1997) Can action research be made more rigorous in a positivistic sense? 
The contribution of an interpretive approach. Journal of Systems and Information Technology, 1, 1-24.

Kohli, R. \& Kettinger, W. (2004) Informating the clan: controlling physicians' costs and outcomes. MIS Quarterly, 28, 363-394.

Latour, B. (1987) Science in Action: How to Follow Scientists and Engineers through Society. Harvard University Press, Cambridge, MA, USA.

Lau, F. (1997) A review on the use of action research in information systems studies. In: Information Systems and Qualitative Research, Lee, A.S., Liebenau, J. \& DeGross, J. (eds), pp. 31-68. Chapman and Hall, London.

Levin, M. (1993) Creating networks for rural economic development in Norway. Human Relations, 46, 193-218.

Lindgren, R., Stenmark, D. \& Ljungberg, J. (2003) Rethinking competence systems for knowledge-based organizations. European Journal of Information Systems, 12, 18-29.

Majchrzak, A. (1997) Software to support socio-technical design: the case of TOP-integrator. In: Design of Computing Systems, Salvendy, G., Smith, M. \& Koubek, R. (eds), pp. 229-231. Elsevier, New York, NY, USA.

Majchrzak, A. \& Finley, L. (1995) A practical theory and tool for specifying socio-technical requirements to achieve organizational effectiveness. In: The Symbiosis of Work and Technology, Benders, J., de Haan, J. \& Bennett, D. (eds), pp. 95-116. Taylor and Francis, London.

Majchrzak, A. \& Gasser, L. (2000) TOP modeler. Information, Knowledge \& Systems Management, 2, 95-110.

Markus, M.L., Majchrzak, A. \& Gasser, L. (2002) A design theory for systems that support emergent knowledge processes. MIS Quarterly 26, 179-212.

Mason, J. (2004) Qualitative Researching. Sage Publications, Thousand Oaks, CA, USA.

Mathiassen, L. (2002) Collaborative practice research. Information Technology \& People, 15, 321-345.

Mathiassen, L., Pries-Heje, J. \& Ngwenyama, O. (2002) Improving Software Organizations - From Principles to Practice. Addison-Wesley, Upper Saddle River, NJ, USA.

McKay, J. \& Marshall, P. (2001) The dual imperatives of action research. Information Technology \& People, 14, 46-59.

Mingers, J. (2001) Combining IS research methods: towards a pluralist methodology. Information Systems Research, 12, 240-259.

Orlikowski, W. \& Baroudi, J. (1991) Studying information technology in organizations: research approaches and assumptions. Information Systems Research, 2, 1-62.

Rapoport, R. (1970) Three dilemmas in action research. Human Relations, 23, 499-513.
Salmon, M. (1989) Explanation in the social sciences. In: Scientific Explanation; Minnesota Studies in the Philosophy of Science. Kitcher, P. \& Salmon, W. (eds), pp. 3-220. University of Minnesota Press, Minneapolis, MN, USA.

Simon, H. (1981) The Sciences of the Artificial. MIT Press, Cambridge, MA, USA.

Susman, G. \& Evered, R. (1978) An assessment of the scientific merits of action research. Administrative Science Quarterly, 23, 582-603.

Walls, J., Widmeyer, G. \& Sawy, E.O. (1992) Building an information system design theory for vigilant EIS. Information Systems Research, 3, 36-59.

Wastell, D., Kawalek, P., Langmead-Jones, P. \& Ormerod, R. (2004) Information systems and partnership in multiagency networks: an action research project in crime reduction. Information and Organization, 14, 189-210.

Webster, J. \& Watson, R. (2002) Analyzing the past to prepare for the future: writing a literature review. MIS Quarterly, 26, xiii-xxiii.

\section{Biographies}

Matt Germonprez is an Assistant Professor at the University of Wisconsin - Eau Claire. Before coming to UW-Eau Claire, he was an Assistant Professor at Case Western Reserve University. His research focuses on computersupported group practices. He relies on the examination of individual and group actions to determine how technology is tailored and used to resolve distorted communications. Secondary streams of study include service-oriented architecture, theory use, mobile computing and interface design. He teaches object-oriented programming, distributed computing and network design. He has been published in the Journal of AIS, Information Systems Journal, Communications of AIS, Organization Studies and IFIP Transactions.

Mike W. Chiasson is currently a Senior Lecturer at Lancaster University's Management School in the Department of Management Science. Before joining Lancaster University, he was an Associate Professor at the Haskayne School of Business, University of Calgary, and a Post-doctoral Fellow at the Institute for Health Promotion Research at the University of British Columbia. His research examines how social context affects IS development and implementation using a range of social theories (actor network theory, structuration theory, critical social theory, ethnomethodology, communicative action, powerknowledge, deconstruction and institutional theory). In studying these questions, he has examined various development and implementation issues (privacy, user involve- 
ment, diffusion, outsourcing, cybercrime and system development conflict) within medical, legal, engineering, entrepreneurial and governmental settings. Most of his work has been qualitative in nature, with a strong emphasis on 'participant' observation.

Lars Mathiassen is Georgia Research Alliance Eminent Scholar, Professor at the Computer Information Systems Department and co-Founder of The Center for Process Innovation at Georgia State University. His research focuses on development of software and information services on information technology-enabled innovation of business processes and on management and facilitation of organizational change processes. He approaches innovation and improvement initiatives with a strong focus on people skills and collaborative processes while at the same time emphasizing adoption of state-of-the-art technologies and methods. He has published extensively in major information systems and software engineering journals and has co-authored several books on the subject, including Professional Systems Development (Prentice Hall, 1990), Computers in Context: The Philosophy and Practice of Systems Design (Blackwell Science, 1993), Object Oriented Analysis \& Design (Marko Publishing House, 2000) and Improving Software Organizations: From Principles to Practice (Addison-Wesley, 2002). He is the co-Founder of Scandinavian Journal of Information Systems and has served as Senior Editor for MIS Quarterly.

\section{APPENDIX: CODED ARTICLES}

\begin{tabular}{|c|c|c|c|c|}
\hline & Author & $\begin{array}{l}\text { Dominant (D), } \\
\text { Sequential (S) }\end{array}$ & $\begin{array}{l}\text { Research dominant } \\
\text { (RD), Problem-solving } \\
\text { dominant (PSD), } \\
\text { Interactive (I) }\end{array}$ & Year \\
\hline \multirow[t]{5}{*}{ Data Base } & Iversen, Nielsen \& Nørbjerg & $\mathrm{D}$ & PSD & 1999 \\
\hline & de Vreede \& de Bruijn & S & $\mathrm{RD}$ & 1999 \\
\hline & Hasan, Hyland, Dodds \& Veeraraghaven & $S$ & I & 2000 \\
\hline & Kawalek \& Wood-Harper & S & PSD & 2002 \\
\hline & Chiasson & $\mathrm{D}$ & I & 2003 \\
\hline \multirow[t]{10}{*}{ MISQ } & Kaiser \& Bostrom & S & $\mathrm{RD}$ & 1982 \\
\hline & Baskerville \& Stage & $S$ & $\mathrm{RD}$ & 1996 \\
\hline & Straub \& Welke & $\mathrm{D}$ & $\mathrm{RD}$ & 1998 \\
\hline & Markus, Majchrzak \& Gasser & S & $\mathrm{RD}$ & 2002 \\
\hline & Braa, Monteiro \& Sahay & $\mathrm{D}$ & PSD & 2004 \\
\hline & Iversen, Mathiassen \& Nielsen & D & 1 & 2004 \\
\hline & Kohli \& Kettinger & S & I & 2004 \\
\hline & Lindgren, Henfridsson \& Schultze & $\mathrm{D}$ & $\mathrm{RD}$ & 2004 \\
\hline & Martensson \& Lee & S & PSD & 2004 \\
\hline & Street \& Meister & $\mathrm{S}$ & I & 2004 \\
\hline \multirow[t]{3}{*}{ JMIS } & de Vreede & $\mathrm{D}$ & I & 1998 \\
\hline & Briggs, Adkins, Mittleman, Kruse, Miller \& Nunamaker & $\mathrm{D}$ & $\mathrm{RD}$ & 1999 \\
\hline & Hengst \& de Vreede & $\mathrm{D}$ & PSD & 2004 \\
\hline \multirow[t]{11}{*}{ ISJ } & Allen, Colligan, Finnie \& Kern & S & $\mathrm{RD}$ & 2000 \\
\hline & Davison \& Vogel & $\mathrm{D}$ & I & 2000 \\
\hline & Peppard & $\mathrm{D}$ & PSD & 2000 \\
\hline & Koch & $\mathrm{S}$ & PSD & 2001 \\
\hline & Vidgen & $S$ & 1 & 2002 \\
\hline & Grant \& Ngwenyama & $\mathrm{S}$ & $\mathrm{RD}$ & 2003 \\
\hline & Kautz \& Nielsen & $S$ & PSD & 2004 \\
\hline & Davison, Martinsons \& Kock & S & PSD & 2004 \\
\hline & Tang & $\mathrm{S}$ & I & 2004 \\
\hline & Ibbott \& O’Keefe & $\mathrm{D}$ & PSD & 2004 \\
\hline & Vrechopolous, Pramataris, Doukidis \& Lekatos & $S$ & PSD & 2003 \\
\hline
\end{tabular}


APPENDIX: cont.

\begin{tabular}{|c|c|c|c|c|}
\hline & Author & $\begin{array}{l}\text { Dominant (D), } \\
\text { Sequential (S) }\end{array}$ & $\begin{array}{l}\text { Research dominant } \\
\text { (RD), Problem-solving } \\
\text { dominant (PSD), } \\
\text { Interactive (I) }\end{array}$ & Year \\
\hline \multirow[t]{16}{*}{ ITP } & Parker \& Swatman & S & PSD & 1995 \\
\hline & Kock \& McQueen & S & 1 & 1995 \\
\hline & Heiskanen & $S$ & 1 & 1995 \\
\hline & Nosek \& Mandviwalla & S & PSD & 1996 \\
\hline & Songkhla & $S$ & PSD & 1997 \\
\hline & Farbey, Land \& Targett & $\mathrm{D}$ & PSD & 1999 \\
\hline & Gregor \& Jones & $S$ & PSD & 1999 \\
\hline & Olesen \& Myers & S & I & 1999 \\
\hline & Davison & $\mathrm{D}$ & $\mathrm{RD}$ & 2001 \\
\hline & Mumford & S & 1 & 2001 \\
\hline & Chiasson \& Dexter & $\mathrm{S}$ & I & 2001 \\
\hline & Mathiassen & $\mathrm{D}$ & 1 & 2002 \\
\hline & Rose & $\mathrm{D}$ & 1 & 2002 \\
\hline & Davison \& Martinsons & $\mathrm{D}$ & $\mathrm{RD}$ & 2002 \\
\hline & Finnegan, Galliers \& Powerll & $\mathrm{D}$ & $\mathrm{RD}$ & 2003 \\
\hline & Burstein \& Linger & $\mathrm{D}$ & PSD & 2003 \\
\hline \multirow[t]{7}{*}{ EJIS } & Hitchman & S & $\mathrm{RD}$ & 1997 \\
\hline & Kanellis, Lycett \& Paul & $S$ & PSD & 1999 \\
\hline & Ledington \& Ledington & S & PSD & 1999 \\
\hline & Salmela, Lederer \& Roponen & $\mathrm{D}$ & PSD & 2000 \\
\hline & Simon & S & 1 & 2000 \\
\hline & Akkermans \& van Helden & $\mathrm{D}$ & $\mathrm{RD}$ & 2002 \\
\hline & Lindgren, Stenmark \& Ljungberg & $\mathrm{D}$ & 1 & 2003 \\
\hline \multirow[t]{4}{*}{$I \& M$} & Ngwenyama & $\mathrm{D}$ & $\mathrm{RD}$ & 1993 \\
\hline & Stein & $\mathrm{D}$ & PSD & 1995 \\
\hline & Kock & S & $\mathrm{RD}$ & 1998 \\
\hline & Lee & S & PSD & 2002 \\
\hline \multirow[t]{7}{*}{$1 \& O$} & Jonsson & $\mathrm{D}$ & PSD & 1992 \\
\hline & Reeves-Ellington \& Anderson & S & 1 & 1997 \\
\hline & Baskerville \& Pries-Heje & S & PSD & 1999 \\
\hline & Braa \& Vidgen & S & PSD & 1999 \\
\hline & Thompson & $\mathrm{S}$ & PSD & 2002 \\
\hline & Wastell, Kawalek, Langmead-Jones \& Omerod & S & PSD & 2004 \\
\hline & Henfridsson \& Lindgren & S & $\mathrm{RD}$ & 2005 \\
\hline
\end{tabular}

JMIS, Journal of Management Information Systems. 